\title{
Preface to the Proceedings of the International Conference on Trends and Perspectives in Linear Statistical Inference LINSTAT'2008 in Celebration of Tadeusz Caliński's 80th Birthday
}

\author{
Augustyn Markiewicz • Götz Trenkler
}

Published online: 7 August 2009

(C) Springer-Verlag 2009

The conference LINSTAT'2008 was held at the Mathematical Research and Conference Center of the Institute of Mathematics of the Polish Academy of Sciences in Będlewo, Poland, on April 21-25. The conference was organized and supported by Stefan Banach International Mathematical Center, Committee of Mathematics of the Polish Academy of Sciences, Faculty of Mathematics and Computer Science and Institute of Socio-Economic Geography and Spatial Management of the Adam Mickiewicz University, Department of Mathematical and Statistical Methods of the Poznan University of Life Sciences, Institute of Plant Genetics of the Polish Academy of Sciences, Faculty of Mathematics, Computer Science and Econometrics of the University of Zielona Góra, Polish Biometric Society, and Polish Mathematical Society, with sponsoring by GlaxoSmithKline Pharmaceuticals. The conference was endorsed by the Council of Statistics of the Committee of Mathematics of the Polish Academy of Science as a 34th conference in the series "Mathematical Statistics".

The International Scientific Committee comprised Augustyn Markiewicz (Poland; chair), João T. Mexia (Portugal), Simo Puntanen (Finland), Götz Trenkler (Germany), Dietrich von Rosen (Sweden), and Roman Zmyślony (Poland). The Local Organizing Committee was chaired by Katarzyna Filipiak, and included Tomasz Kossowski, Augustyn Markiewicz (vice-chair), Marcin Przystalski, Agnieszka Suchocka, and Waldemar Wołyński.

The aim of this conference was to bring together researchers sharing an interest in a variety of aspects of statistics and its applications and offer them a possibility to discuss current developments in these subjects.

\footnotetext{
A. Markiewicz $(\varangle)$

Department of Mathematical and Statistical Methods,

Poznań University of Life Sciences, Poznań, Poland

e-mail: amark@up.poznan.pl

G. Trenkler

Fakultät Statistik, Technische Universitaet Dortmund, Dortmund, Germany
} 
The conference also celebrated the 80th birthday of Professor Tadeusz Caliński. Tadeusz Caliński was born on September 4, 1928, in Poznań. In 1953 he received the M.Sc. degree in Agriculture from the Agricultural University of Poznań, followed by a three-years study of mathematics at the Adam Mickiewicz University of Poznań. The Ph.D. in Agriculture and Forestry he obtained in 1961 and the D.Sc. in 1966, both from the Agricultural University of Poznań. From 1953 to 1964 T. Caliński worked in the Department of Genetics and Plant Breeding, Agricultural University of Poznań. From 1964 to 1988 he was a faculty member of the Department of Statistical Methods, Agricultural University of Poznań (from 1971 Department of Mathematical and Statistical Methods). From 1968 till 1984 he was the Head of this Department. He became Emeritus Professor in 1988.

He got two titles of Honoris Causa Doctoris: in 1998 awarded by the Agricultural University of Poznań and in 2008 awarded by the Warsaw University of Life Sciences.

The main achievements of Professor T. Caliński include foundation of the Poznań inter-university school in mathematical statistics and biometry, promotions of $24 \mathrm{Ph} . \mathrm{D}$. students in mathematical statistics and biometry, stimulation of interest in mathematical statistics and biometry among mathematicians, particularly by initiating and then chairing for several years the Commission for Mathematical Statistics at the Committee for the Mathematical Sciences of the Polish Academy of Sciences, promotion and dissemination of statistical and biometrical methods among students and research workers from various fields of science, both by teaching and consulting as well as initiation of and contribution to fruitful international co-operation between Polish statisticians and biometricians and their colleagues in various countries (particularly in Netherlands, France, Italy, Great Britain, Germany, Japan and Portugal).

The International Scientific Committee selected the best talks presented by Ph.D. students and young researchers. The winners were: the 1st prize - Wojciech Rejchel (Poland), the 2nd prize - Thomas Rusch (Austria), the 3rd prize-Klaus Nordhausen (Finland), and the prize for the best poster-Alin Aylin (Turkey).

The conference is a continuation of earlier international meetings, which provided a good occasion for a review of important research in statistics. The previous international conferences devoted to linear statistical inference were organized in Poland in:

- Wisła (1977, 1978, 1980),

- Poznań (1984),

- Olsztyn (1988),

- Poznań - LINSTAT'93,

- Jachranka (1996),

- Łagów - STAT'98,

- Będlewo - STATLIN'03.

The attendants of the LINSTAT'2008 shared the common opinion that the conference was extremely fruitful and well organized. The next meeting in the LINSTAT series will be held in Tomar, Portugal, 27-31 July 2010. The LINSTAT'2010 Conference is 
chaired by João T. Mexia (Scientific Committee) and Francisco Carvalho (Organizing Committee) and the official web page is http://www.linstat2010.ipt.pt.

This Special Issue of Statistical Papers contains selected papers presented at the LINSTAT'2008 Conference. They are mainly devoted to estimation, prediction and testing in linear univariate and multivariate models, statistical inference in a mixed linear model - estimation and testing of variance components, design and analysis of experiments, including optimality and comparison of linear experiments. 